\title{
Preservation of active incretin hormones by inhibition of dipeptidyl peptidase IV suppresses meal-induced incretin secretion in dogs
}

\author{
C F Deacon, S Wamberg ${ }^{1}$, P Bie ${ }^{1}$, T E Hughes ${ }^{2}$ and J J Holst \\ Department of Medical Physiology, The Panum Institute, University of Copenhagen, Blegdamsvej 3, DK-2200 Copenhagen N, Denmark \\ ${ }^{1}$ Department of Physiology and Pharmacology, University of Southern Denmark, Winsløwparken 21, DK-5000 Odense, Denmark \\ ${ }^{2}$ Novartis Institute for Biomedical Research, 556 Morris Avenue, Summit, New Jersey 07901-1398, USA \\ (Requests for offprints should be addressed to C F Deacon; Email: deacon@mfi.ku.dk)
}

\begin{abstract}
The incretin hormones glucagon-like peptide-1 (GLP-1) and glucose-dependent insulinotropic polypeptide (GIP) are degraded by dipeptidyl peptidase IV (DPP IV), thereby losing insulinotropic activity. DPP IV inhibition reduces exogenous GLP-1 degradation, but the extent of endogenous incretin protection has not been fully assessed, largely because suitable assays which distinguish between intact and degraded peptides have been unavailable. Using newly developed assays for intact GLP-1 and GIP, the effect of DPP IV inhibition on incretin hormone metabolism was examined.

Conscious dogs were given NVP-DPP728, a specific DPP IV inhibitor, at a dose that inhibited over $90 \%$ of plasma DPP IV for the first $90 \mathrm{~min}$ following treatment. Total and intact incretin concentrations increased $(P<0 \cdot 0001)$ following a mixed meal, but on control days (vehicle infusion), intact peptide concentrations were lower $(P<0 \cdot 01)$ than total peptide concentrations $(22 \cdot 6 \pm 1 \cdot 2 \%$ intact GIP; $10 \cdot 1 \pm 0 \cdot 4 \%$ intact GLP-1).
\end{abstract}

Following inhibitor treatment, the proportion of intact peptide increased $(92.5 \pm 4.3 \%$ intact GIP, $P<0.0001$; $99 \cdot 0 \pm 22 \cdot 6 \%$ intact GLP-1, $P<0 \cdot 02$ ). Active (intact) incretins increased after NVP-DPP728 (from $4797 \pm 364$ to $10649 \pm 106 \mathrm{pM} \times \min$ for GIP, $P<0 \cdot 03$; from $646 \pm$ 134 to $2822 \pm 528 \mathrm{pM} \times \min$ for GLP-1, $P<0 \cdot 05)$. In contrast, total incretins fell (from $21632 \pm 654$ to $12084 \pm 1723 \mathrm{pM} \times \min$ for GIP, $P<0.002$; from $5145 \pm 677$ to $3060 \pm 601 \mathrm{pM} \times \min$ for GLP-1, $P<0 \cdot 05)$. Plasma glucose, insulin and glucagon concentrations were unaltered by the inhibitor.

We have concluded that DPP IV inhibition with NVP-DPP728 prevents N-terminal degradation of endogenous incretins in vivo, resulting in increased plasma concentrations of intact, biologically active GIP and GLP-1. Total incretin secretion was reduced by DPP IV inhibition, suggesting the possibility of a feedback mechanism.

Journal of Endocrinology (2002) 172, 355-362

\section{Introduction}

The two incretin hormones, glucagon-like peptide-1 (GLP-1) and glucose-dependent insulinotropic polypeptide (GIP, also referred to as gastric inhibitory polypeptide), are secreted from the intestinal mucosa ( $\mathrm{L}-$ and $\mathrm{K}$-cells respectively) in response to the presence of nutrients (Brown et al. 1989, Holst 1997), and act to potentiate meal-induced secretion of insulin (Creutzfeldt \& Ebert 1985, Nauck et al. 1993, Scrocchi et al. 1998, Miyawaki et al. 1999). Together with inhibitory effects on gastric motility and acid secretion (Brown et al. 1970, Wettergren et al. 1993), they play an important role in limiting post-prandial glucose excursions.

It has been shown convincingly in in vitro studies that the enzyme dipeptidyl peptidase IV (DPP IV, EC 3.4.14.5) can degrade both GLP-1 and GIP (Kieffer et al. 1995, Mentlein et al. 1993, Deacon et al. 1995a, Pauly et al. 1996), and it is now accepted that DPP IV is the most important enzyme for the initial inactivation of GLP-1 in vivo (Holst \& Deacon 1998). This is due to the removal of the N-terminal dipeptide, which renders GLP-1 incapable of activating its receptor (Knudsen \& Pridal 1996). The development of specific analytical techniques capable of distinguishing between the intact peptide and the truncated metabolite has been crucial in revealing the key role of DPP IV in determining the biological activity of GLP-1 in vivo (Deacon et al. 1995a). GIP has not received the same attention, largely because of the lack of suitable methodology since, until recently, most, if not all, assays for GIP have been unable to distinguish between intact GIP (1-42) and the N-terminally truncated metabolite, GIP (3-42), generated as a result of DPP IV action. This necessitated high-pressure liquid chromatography (HPLC) analysis of plasma samples to support the suggestion that DPP IV may have a role in degrading exogenous GIP in rats (Kieffer et al. 1995). The recent development of a specific N-terminally directed assay for GIP has revealed 
the potential role of DPP IV in in vivo inactivation of endogenous GIP in humans (Deacon et al. 2000), since GIP (3-42) was shown to be the predominant circulating molecular form.

The discovery of the critical role of DPP IV in GLP-1 metabolism formed the basis for the suggestion that DPP IV inhibition may be a novel method for treating diabetic hyperglycaemia (Deacon et al. 1995b, Holst \& Deacon 1998), since inhibiting the enzyme would be likely to protect GLP-1 from degradation and, therefore, improve its ability to lower blood glucose. Thus, DPP IV inhibition proved to be remarkably efficient at preventing in vivo degradation of exogenously infused GLP-1, and this effect was associated with augmented insulin secretion in response to intravenous glucose in anaesthetised pigs (Deacon et al. 1998). Subsequently, DPP IV inhibition has been shown to improve glucose tolerance in rodent models of insulin resistance (Pederson et al. 1998, Balkan et al. 1999, Ahrén et al. 2000). This effect was attributed to the higher concentrations of intact biologically active GLP-1 arising as a consequence of inhibition of DPP IV activity, since specific analyses showed that the inhibitor abolished degradation of endogenous GLP-1 (Balkan et al. 1999). The effect on GIP was not examined, although it was postulated that increased levels of intact GIP would contribute to the glucose-lowering effect.

The present study aimed to examine the effect of a novel, highly specific and potent DPP IV inhibitor, NVP-DPP728 (Hughes et al. 1999), on the hormonal responses to a mixed meal in non-anaesthetised dogs, with a view to identifying the extent to which DPP IV is involved in inactivation of endogenous incretins and to what extent it would be possible to protect them from degradation. In addition to measuring the pancreatic responses, the study relies upon recently developed assays for the incretin hormones, which are capable of measuring specifically the non-degraded biologically active forms of GLP-1 and GIP (Deacon et al. 2000).

\section{Materials and Methods}

\section{DPP IV inhibitor}

1-[[[2-[(5-cyanopyridin-2-yl)amino]ethyl]amino]acetyl]2-cyano-(S)-pyrrolidine (NVP-DPP728) is a slowbinding, rapidly reversible inhibitor of DPP IV with a $K_{\mathrm{i}}$ of $11 \mathrm{nM}$ (Hughes et al. 1999). It is highly selective for DPP IV relative to other post-proline cleaving enzymes (e.g. prolyl oligopeptidase, aminopeptidase P, DPP II).

\section{Experimental procedure}

This study was approved by the Danish Animal Experiments Inspectorate, according to the guidelines approved by the Member States of the Council of Europe for the use of live animals for scientific research. Prior to the study, three female beagle dogs (16-18 months old, 11-14 kg) were accustomed over several months to being restrained in a sling. Animals were fed once daily (SDS Pet Food; Special Diets Services, Witham, Essex, UK; $350 \mathrm{~g}$ ) at approximately $1400 \mathrm{~h}$ and had free access to drinking water. The dogs were fasted from $1500 \mathrm{~h}$ on the day prior to the experimental day, but water was withheld from $0000 \mathrm{~h}$ on the morning of the experiment. On 4 days, each separated by $2-3$ weeks, each animal received on two occasions either the DPP IV inhibitor (NVP-DPP728) or vehicle.

In the morning of the experimental day, the dog was placed in the sling and a sterile catheter (Intracath; Becton Dickinson, Sandy, UT, USA) was introduced into the right atrium via the external jugular vein (or in a few cases via the saphenous vein), and used for infusion of the inhibitor or vehicle and for blood sampling. The animal was then allowed a 30-min equilibration period. Prior to taking each blood sample, the catheter was flushed by withdrawing $2-3 \mathrm{ml}$ blood. This was reinfused after the sample had been collected, and the catheter was flushed with heparinised (16 International equivalents (IE)/ml) isotonic saline solution. At $-30 \mathrm{~min}$, a basal blood sample was taken, and the inhibitor $(1 \mathrm{mg} / \mathrm{kg}$, dissolved in sterile isotonic saline solution) or vehicle was administered by slow intravenous infusion. The inhibitor dose was selected to provide equivalent compound exposure and pharmacodynamic effects to a $100 \mathrm{mg}$ dose in man, which has been reported to increase active GLP-1 levels during meal tests (Rothenberg et al. 2000). A further blood sample was taken at $-5 \mathrm{~min}$. At $0 \mathrm{~min}$, a blood sample was taken and a test meal $(9 \mathrm{ml} / \mathrm{kg}$ of a mixture of commercial sour cream (crème fraïche, 18\% fat; $100 \mathrm{ml}$ ) and sucrose solution (1 M; $100 \mathrm{ml})$ ) was given by oral gavage, using a $60 \mathrm{~cm}$ long paediatric feeding tube. Additional blood samples were collected at 15, 30, 60, 90, 120 and $150 \mathrm{~min}$. At the end of the experiment, the venous catheter was removed.

Blood samples for hormone analysis $(4 \mathrm{ml})$ were collected into chilled Minisorb tubes containing EDTA (6.75 mM, final concentration), aprotinin (675 kallikrein inhibitory units $/ \mathrm{ml}$ blood) and valine-pyrrolidide (a specific DPP IV inhibitor, provided by Dr Orin Tempkin, Novartis Pharmaceuticals, East Hannover, NJ, USA; $0.01 \mathrm{mM}$, final concentration). Samples for determination of glucose and DPP IV activity $(2 \mathrm{ml})$ were collected into tubes containing heparin $(<20 \mathrm{IE} / \mathrm{ml})$. The amount of blood taken on each occasion represented approximately $5 \%$ of the total blood volume.

All samples were stored on ice until centrifugation at $4{ }^{\circ} \mathrm{C}$, after which plasma was separated and stored at $-20{ }^{\circ} \mathrm{C}$ until analysis.

\section{Hormonal analysis}

Plasma levels of intact and total incretin hormones were measured using specific radioimmunoassays (RIAs) which 
were validated by HPLC as described previously (Deacon et al. 1995a, 2000).

GLP-1 concentrations were determined using assays directed towards each end of the molecule with human GLP-1 standards (canine GLP-1 is thought to be identical to human GLP-1). N-terminal immunoreactivity was measured using a newly developed assay for the intact $\mathrm{N}$-terminus of GLP-1. Antibodies were raised by immunising rabbits with the synthetic sequence, GLP-1 (7-16)cys (Genosys Biotechnologies (Europe) Ltd, Cambridge, Cambs, UK), coupled to keyhole limpet haemocyanin using $m$-maleimidobenzoyl- $N$-hydroxysuccinimide ester, as described by Dyrberg \& Kofod (1990). Antiserum 98302 could be used in a final dilution of 1:65 000 and endows the assay with a detection limit of approximately $5 \mathrm{pM}$ and an $\mathrm{ED}_{50}$ of $80 \cdot 8 \pm 3 \cdot 4 \mathrm{pM}$. The assay is specific for the intact N-terminus of GLP-1, and cross-reacts less than $0 \cdot 1 \%$ with GLP-1 (9-36)amide, or with the structurally related peptides GLP-1 (1-36)amide, GIP (1-42), GIP (3-42), GLP-2 (1-33), GLP-2 (3-33) or glucagon at concentrations of up to $100 \mathrm{nM}$. It has a cross-reactivity of approximately $4 \%$ with the major proglucagon fragment (proglucagon (72-158)) secreted from the pancreas. Intraassay variation was less than $6 \%$ and interassay variations were approximately 8 and $12 \%$ for 20 and 80 pM standards respectively. Valine-pyrrolidide $(0 \cdot 01 \mathrm{mM}$ final concentration) was added to the assay buffer to prevent N-terminal degradation of GLP-1 during the assay incubation. HPLC supports the use of RIAs with this specificity for determination of intact GLP-1 (Deacon et al. 1995a). Since the presence of both amidated and glycineextended forms of GLP-1 (Mojsov et al. 1987, Ørskov et al. 1989, 1994) in the dog could not be excluded, C-terminal immunoreactivity was determined using two different antisera. Antiserum 89390 (Ørskov et al. 1994) has an absolute requirement for the intact amidated C-terminus of GLP-1 (7-36)amide, and cross-reacts $83 \%$ with GLP-1 (9-36)amide, but less than $0.01 \%$ with the glycine extended form, GLP-1 (7-37), or with C-terminally truncated fragments. Antiserum 92071 (Ørskov et al. 1994) is specific for the C-terminus of GLP-1 (7-37) and cross-reacts fully with GLP-1 (9-37) but less than $0 \cdot 1 \%$ with amidated forms of GLP-1. For all assays, the intra-assay coefficient of variation was less than $6 \%$. Plasma samples were extracted with $70 \%$ ethanol $(\mathrm{v} / \mathrm{v}$, final concentration) before assay, giving recoveries of $75 \%$ (Ørskov et al. 1991).

Total GIP was measured using the C-terminally directed antiserum R65 (Krarup et al. 1983, Krarup \& Holst 1984), which reacts fully with intact GIP and the N-terminally truncated metabolite, GIP (3-42), but not with the so-called $8 \mathrm{kDa}$ GIP, whose chemical nature and relation to GIP secretion is uncertain. The assay has a detection limit of less than $2 \mathrm{pM}$ and an intra-assay variation of approximately $6 \%$. Intact, biologically active GIP was measured using a newly developed assay (Deacon et al. 2000). Briefly, antibodies were raised against the synthetic sequence, GIP (1-10)-cys (Genosys Biotechnologies (Europe) Ltd), as described above. Antiserum 98171 endows the assay with a detection limit of approximately $5 \mathrm{pM}$ and an $\mathrm{ED}_{50}$ of $47 \cdot 5 \pm 2 \cdot 3 \mathrm{pM}$. The assay is specific for the intact N-terminus of GIP, and cross-reacts less than $0 \cdot 1 \%$ with GIP (3-42), or with the structurally related peptides GLP-1 (7-36)amide, GLP-1 (936)amide, GLP-2 (1-33), GLP-2 (3-33) or glucagon at concentrations of up to $100 \mathrm{nM}$. Plasma samples were extracted with ethanol $(70 \% \mathrm{v} / \mathrm{v}$, final concentration), giving recoveries of synthetic GIP added to plasma of $85 \%$. Intra-assay variation was less than $6 \%$ and interassay variations were approximately 8 and $12 \%$ for 20 and $80 \mathrm{pM}$ standards respectively. Valine-pyrrolidide $(0.01 \mathrm{mM}$, final concentration) was added to the assay buffer to prevent N-terminal degradation of GIP during the assay incubation. For both assays, human GIP (Peninsula Laboratories Europe Ltd, St Helens, Merseyside, UK) was used as standard (the sequence of canine GIP has not been determined) and radiolabelled GIP was from Amersham Pharmacia Biotech Ltd (Little Chalfont, Bucks, UK). Separation of bound from free peptide was achieved using plasma-coated charcoal (Ørskov et al. 1987).

Insulin immunoreactivity was measured in unextracted plasma using antiserum 2004 (Ørskov et al. 1991), and glucagon immunoreactivity was determined after ethanol extraction, using the C-terminally directed antiserum 4305, which measures glucagon of pancreatic origin (Ørskov et al. 1991). For both assays, human standards were used (canine glucagon is identical to human glucagon while canine insulin differs only at a single amino acid).

\section{Glucose analysis}

Plasma glucose was determined by the glucose oxidase method using a glucose analyser (YSI Inc., Yellow Springs, OH, USA).

\section{DPP IV activity determination}

DPP IV activity was assessed by a fluorescence assay, using H-glycine-proline-7-amino-4-methylcoumarin (Bachem, King of Prussia, PA, USA) as substrate, as previously described (Deacon et al. 1998).

\section{Calculations and statistical analysis}

The areas under the curve (AUC) for the total and intact forms of each incretin were calculated using the trapezoidal method. For each incretin, the percentage intact peptide was expressed as the AUC for N-terminal immunoreactivity relative to the AUC for C-terminal immunoreactivity. The glucose excursion and amounts of insulin and glucagon secreted in response to the meal are 
expressed as the incremental AUC, calculated after subtraction of the basal concentrations measured in samples before the meal.

Each animal received each treatment (vehicle or inhibitor) on two separate occasions. Therefore, for each individual animal, the mean responses to each treatment were calculated. The final data were then expressed as means \pm s.E.M. $(n=3)$. Data were analysed using GraphPAD InStat software, version 1.13 (San Diego, CA, USA) and Statistica software (Stat Soft Inc., Tulsa, OK, USA). Two-factor analysis of variance for repeated measures with post hoc analysis was used to analyse time-course curves before and after DPP IV inhibition. The AUCs for GLP-1 and GIP (intact and total; before and after DPP IV inhibition) were compared using one-way analysis of variance and post hoc analysis. Two-tailed $t$-tests were used to compare the effect of DPP IV inhibition on the glucose, insulin and glucagon AUCs and the percentage intact GLP-1 and GIP. $P<0 \cdot 05$ was considered significant.

\section{Results}

No adverse reactions, as evaluated by real-time electrocardiogram (ECG) monitoring and absence of gastrointestinal symptoms, to the test meal or the inhibitor were seen in any case.

Plasma DPP IV activity did not differ prior to vehicle or inhibitor treatment. It remained unchanged after vehicle treatment, but was reduced $(P<0.005$ compared to vehicle) by NVP-DPP728, to less than $10 \%$ of basal activity during the first $90 \mathrm{~min}$ after treatment. Thereafter, plasma DPP IV activity gradually increased, reaching $37 \cdot 3 \pm 4 \cdot 7 \%$ of basal activity by $180 \mathrm{~min}$ after inhibitor administration (Fig. 1).

The test meal induced increases in both total (Cterminal immunoreactivity; $P<0 \cdot 0001)$ and intact GIP (N-terminal immunoreactivity; $P<0 \cdot 0001$ ) (Fig. 2). After vehicle treatment total GIP levels were higher $(P<0 \cdot 005)$ than levels of intact peptide, whereas after NVP-DPP728, concentrations were similar, indicating substantial protection of intact GIP (cumulative AUC for the 90-min period following the meal, corresponding to the period of maximal DPP IV inhibition, $10649 \pm 106$ compared with $12084 \pm 1723 \mathrm{pM} \times \min )$. The amount of intact GIP in this period more than doubled, from $4797 \pm$ $364 \mathrm{pM} \times \min$ (controls) to $10649 \pm 106 \mathrm{pM} \times \min ($ inhibitor; $P<0 \cdot 03$ ). In contrast, the amount of total GIP actually fell, from $21632 \pm 654 \mathrm{pM} \times \min$ (control) to $12084 \pm 1723 \mathrm{pM} \times \min$ (inhibitor; $P<0 \cdot 001$ ). When expressed as a percentage of total GIP, the intact peptide accounted for $22.6 \pm 1.2 \%$ (vehicle) and increased $(P<0.0002)$ to $92.5 \pm 4.3 \%$ after the inhibitor.

Both total $(P<0 \cdot 0005)$ and intact $(P<0 \cdot 0001)$ GLP-1 concentrations were also elevated by the test meal (Fig. 3), and again C-terminal levels (the sum of immunoreactivity measured with antisera 89390 and 92071) were greater



Figure 1 Plasma dipeptidyl peptidase (DPP) IV activity in conscious dogs $(n=3)$ after administration of vehicle (isotonic saline solution; $\square$ ) or DPP IV inhibitor (NVP-DPP728; $1 \mathrm{mg} / \mathrm{kg}$; ש), where each animal received each treatment twice. A basal blood sample was taken at $-30 \mathrm{~min}$, after which the vehicle or inhibitor was given as a bolus intravenous dose. DPP IV activity was unaltered by vehicle treatment, but was significantly inhibited by NVP-DPP728 $\left({ }^{*} P<0 \cdot 05,{ }^{* *} P<0 \cdot 005\right)$.

$(P<0 \cdot 01)$ on control days. However, after the inhibitor there was no significant difference in the amount of $\mathrm{N}$ - and C-terminal immunoreactivity $\left(\mathrm{AUC}_{0-90 \mathrm{~min}}\right.$, $2822 \pm 528$ and $3060 \pm 601 \mathrm{pM} \times$ min respectively). The amount of intact GLP-1 increased, from $646 \pm$ $134 \mathrm{pM} \times \min ($ controls) to $2822 \pm 528 \mathrm{pM} \times \min$ (inhibitor; $P<0 \cdot 05$ ), while total GLP-1 (the sum of both C-terminal assays) was reduced, from $5145 \pm$ $677 \mathrm{pM} \times \min$ (control) to $3060 \pm 601 \mathrm{pM} \times \min$ (inhibitor; $P<0 \cdot 05)$. The proportion of intact GLP-1 increased, from $10 \cdot 1 \pm 0 \cdot 4 \%$ (vehicle) to $99 \cdot 0 \pm 22 \cdot 6 \%$ (inhibitor; $P<0.02$ ) of total immunoreactivity, while the use of the two C-terminal assays revealed that $70 \cdot 4 \pm 2 \cdot 2 \%$ of the total GLP-1 immunoreactivity in the dog is found as glycine-extended forms.

Plasma glucose profiles did not alter significantly during the experiment and the glucose excursion was only marginally lower after inhibitor treatment (Fig. 4A; AUC $_{0-90 \text { min }}, 0 \pm 12$ versus $-21 \pm 8 \mathrm{mM} \times \min$, control versus inhibitor; $P=0 \cdot 084)$. The test meal induced significant rises in plasma insulin $(P<0 \cdot 01$; Fig. $4 \mathrm{~B})$, but there was no difference between vehicle and inhibitor treatments $\left(\mathrm{AUC}_{0-90 \mathrm{~min}}, \quad 7249 \pm 461\right.$ versus $5560 \pm$ $2812 \mathrm{pM} \times \min$, control versus inhibitor). Glucagon concentrations were not significantly changed during the experiment (Fig. 4C) and were unaffected by the inhibitor $\left(\mathrm{AUC}_{0-90 \mathrm{~min}}, \quad 163 \pm 31\right.$ versus $51 \pm 97 \mathrm{pM} \times \min$, control versus inhibitor).

\section{Discussion}

In this study, the effects of DPP IV inhibition upon incretin hormone metabolism and upon the response to a 



Figure 2 Increase in plasma concentrations of glucose-dependent insulinotropic polypeptide (GIP) after administration of a mixed meal (arrows) in conscious dogs $(n=3)$ after intravenous administration of vehicle (A) or DPP IV inhibitor (B), where each animal received each treatment twice. The vehicle (isotonic saline solution) or DPP IV inhibitor (NVP-DPP728; $1 \mathrm{mg} / \mathrm{kg}$ ) were given 30 min before the meal. Samples were measured using

C-terminally ( $\mathbf{\square})$ and N-terminally $(\square)$ directed assays for GIP. GIP concentrations increased significantly in response to the meal $(P<0 \cdot 0001)$. C-terminal immunoreactivity was significantly higher than $\mathrm{N}$-terminal immunoreactivity in vehicle-treated animals $\left({ }^{*} P<0 \cdot 05,{ }^{*} P<0 \cdot 01,{ }^{*}{ }^{*} P<0 \cdot 005\right)$, but concentrations were similar after inhibitor treatment.

test meal were examined in non-anaesthetised dogs. The results showed that inhibition of plasma DPP IV activity increases the circulating levels of intact versions of both incretin hormones in response to the presence of nutrients in the intestine while at the same time reducing total incretin concentrations.

It is well accepted that DPP IV is the main enzyme responsible for inactivation of GLP-1 in vivo, but its full significance in terms of GIP's stability has not previously been investigated in detail. Thus, intact GLP-1 makes up under half of total endogenous GLP-1 immunoreactivity in man (Deacon et al. 1995a), pig (Hansen et al. 2000) and rat (Balkan et al. 1999), but it was not until specific inhibitors of the enzyme were shown to prevent degradation of GLP-1 in vivo that the pivotal role of DPP IV was fully confirmed (Deacon et al. 1998, Balkan et al. 1999).
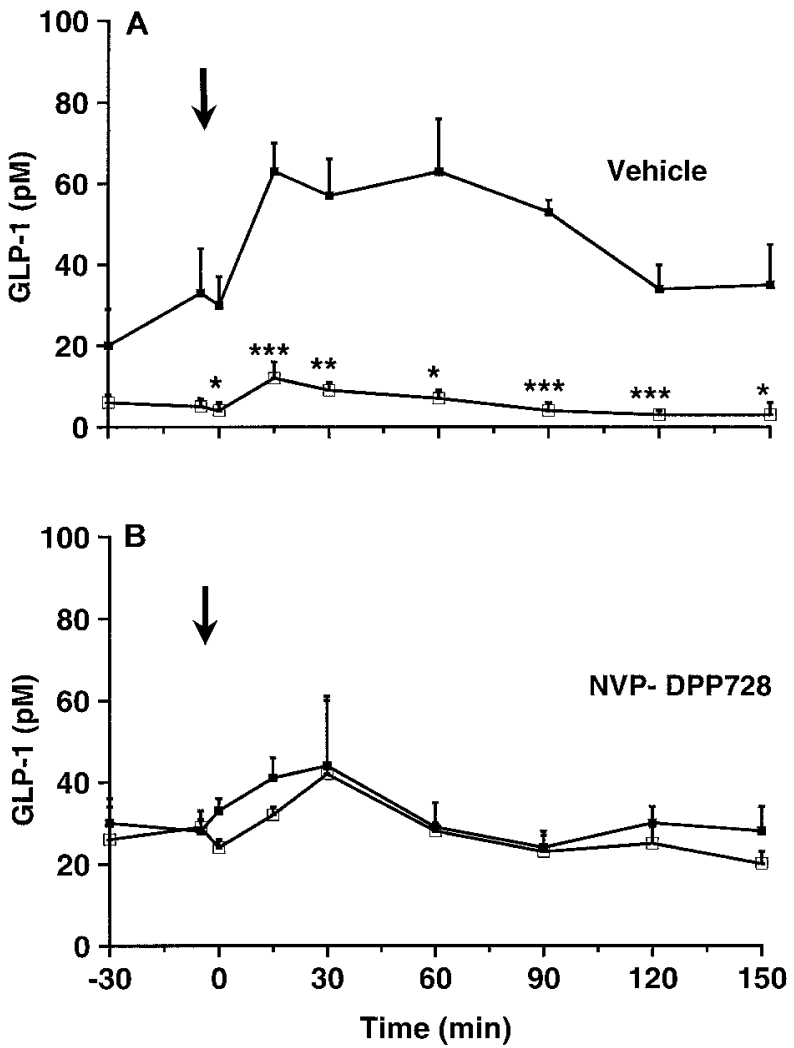

Figure 3 Increase in plasma concentrations of glucagon-like peptide-1 (GLP-1) after administration of a mixed meal (arrows) in conscious dogs $(n=3)$ after intravenous administration of vehicle (A) or DPP IV inhibitor (B), where each animal received each treatment twice. The vehicle (isotonic saline solution) or DPP IV inhibitor (NVP-DPP728; $1 \mathrm{mg} / \mathrm{kg}$ ) were given $30 \mathrm{~min}$ before the meal. Samples were measured using C-terminally $(\boldsymbol{\square})$ and $\mathrm{N}$-terminally $(\square)$ directed assays for GLP-1. GLP-1 concentrations increased significantly in response to the meal $(P<0 \cdot 0001)$. C-terminal immunoreactivity was significantly higher than $\mathrm{N}$-terminal immunoreactivity in vehicle-treated animals $\left({ }^{*} P<0 \cdot 05\right.$, $\left.{ }^{* *} P<0 \cdot 01,{ }^{* * *} P<0 \cdot 005\right)$, but concentrations were similar after inhibitor treatment.

Likewise, in vitro studies have confirmed that GIP is a substrate for DPP IV (Mentlein et al. 1993, Kieffer et al. 1995, Pauly et al. 1996), but the enzyme's role in vivo has only been indicated indirectly by identification of the N-terminally truncated metabolite (Kieffer et al. 1995, Deacon et al. 2000). The results of the present study demonstrated that specific inhibition of DPP IV results in substantial protection of the biologically active forms of both endogenous incretin hormones. It is, therefore, highly likely that the mechanism of action of DPP IV inhibitors in improving glucose tolerance (Pederson et al. 1998, Balkan et al. 1999, Ahrén et al. 2000) involves both incretin hormones, as was suggested by Balkan et al. (1999).

NVP-DPP728 markedly reduced plasma DPP IV activity during the first $2 \mathrm{~h}$, but later, as DPP IV activity 

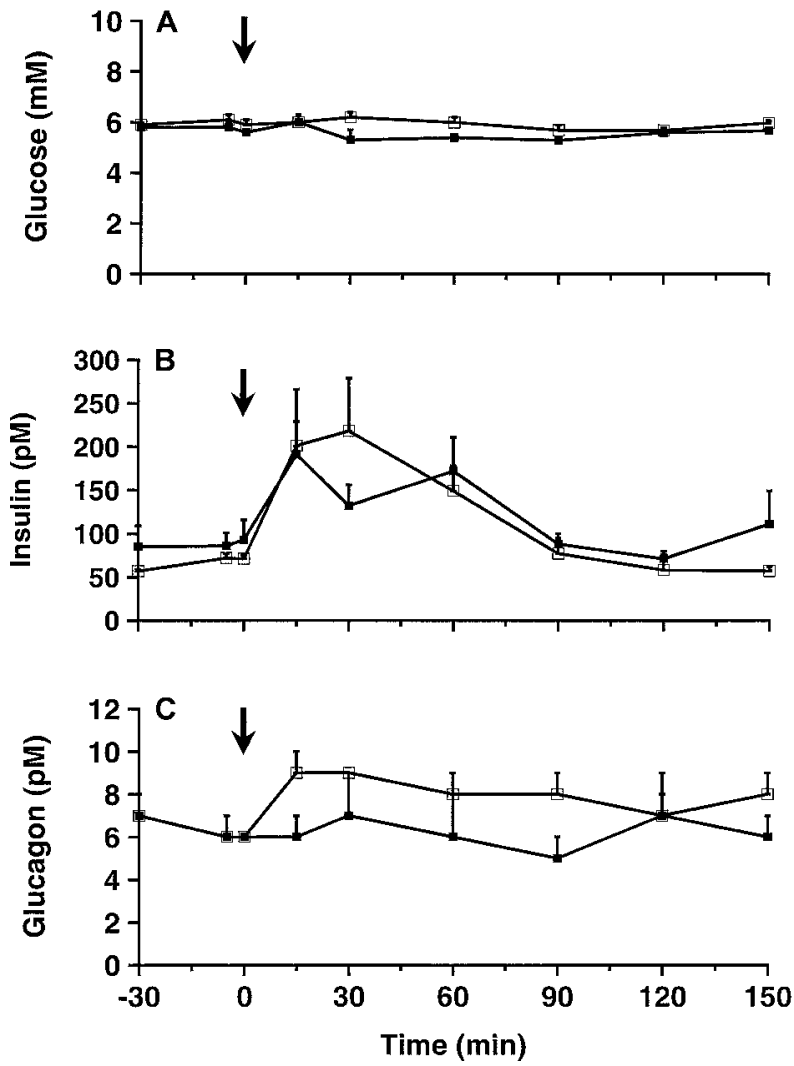

Figure 4 Plasma glucose (A), insulin (B) and glucagon (C) profiles after administration of a mixed meal (arrows) in conscious dogs $(n=3)$ after intravenous administration of vehicle $(\square)$ or DPP IV inhibitor ( $\mathbf{\square})$, where each animal received each treatment twice. The vehicle (isotonic saline solution) or DPP IV inhibitor (NVP-DPP728; $1 \mathrm{mg} / \mathrm{kg}$ ) were given $30 \mathrm{~min}$ before the meal. Glucose and glucagon concentrations were unaltered during the experiment and were not affected by either treatment. Insulin concentrations increased in response to the meal $(P<0.01)$, but there were no differences between vehicle or inhibitor treatment at any time-point.

began to increase, there was also a gradual increase in levels of the N-terminally truncated metabolites. However, during the period of maximal inhibition, NVPDPP728 treatment clearly increased concentrations of the biologically active forms of both GLP-1 and GIP, approximately doubling plasma levels of intact GIP found in response to the meal, while intact GLP-1 concentrations increased fourfold. However, it is intriguing to note that the total response of both incretins, as determined using the C-terminal assays, actually fell in response to the inhibitor. DPP IV inhibition reduces the metabolic clearance and increases the plasma half-life of the active forms of both incretin hormones (Deacon et al. 1998, 2001). However, neither the metabolic clearance nor the plasma half-life of C-terminal GLP-1 or GIP immunoreactivity is affected by DPP IV inhibition (Deacon et al. 1998, 2001), which indicates that the reduction in total incretin levels found after NVP-DPP728 reflects reduced secretion. This, therefore, is suggestive of a feedback mechanism, an effect which has previously been indicated from studies in humans, where exogenous GLP-1 (7-37) infusion led to a reduction in levels of endogenous amidated GLP-1 (ToftNielsen et al. 1999). In the present study, the elevated concentrations of endogenous intact forms of the incretins may themselves restrict further secretion from the $\mathrm{K}$ - and $\mathrm{L}-$ cells. Whether this is a direct relationship (i.e. intact GIP inhibits K-cell secretion while intact GLP-1 influences L-cell secretion) cannot be concluded from the present study. However, in the case of GLP-1, current evidence points to an indirect inhibitory relationship between GLP-1 secretion and the L-cell. Thus, GLP-1 was reported to release somatostatin from isolated rat intestinal cultures (Brubaker et al. 1997) and the isolated, vascularly perfused porcine ileum (Hansen et al. 2000). Furthermore, somatostatin itself inhibits GLP-1 secretion, leading to the suggestion that GLP-1 limits its own secretion by activating a somatostatin-mediated paracrineinhibitory pathway (Hansen et al. 2000). An inhibitory relationship has been established between insulin and GIP secretion (Stockmann et al. 1984) although, in the present study, insulin levels did not change significantly. Additionally, it cannot be excluded that DPP IV inhibition may protect some other inhibitory factor from degradation.

Determination of endogenous GLP-1 concentrations is complicated by the fact that two forms of the peptide are produced. Thus, in man, the predominant forms $(>75 \%$; Orskov et al. 1989, 1994) of GLP-1 are C-terminally amidated, while in pigs (Hansen et al. 2000) and rats (Mojsov et al. 1987) at least half is glycine-extended. Both forms have identical effects on insulin and glucagon secretion (and therefore blood glucose concentrations) (Orskov et al. 1993) and on gastric acid secretion (Wettergren et al. 1998), but the C-terminal amidation seems to protect the peptide from C-terminal degradation in the plasma (Wettergren et al. 1998). As the present study shows, both amidated and glycine-extended GLP-1 are also found in dogs, with the glycine-extended forms making up the majority (70\%) of the total circulating peptide. This means that while, in man, the assay for the amidated C-terminus used in the present study will give a relatively reliable measure of total (intact plus N-terminally truncated metabolite) GLP-1 concentrations, the use of a single C-terminal assay is going to underestimate secretion in the pig, rat and dog. However, by determining total plasma GLP-1 using assays for both the amidated and the glycine-extended forms of GLP-1, the present study shows that DPP IV inhibition results in equal concentrations being determined with the $\mathrm{N}$-terminal and the sum of the two C-terminal assays, i.e. the inhibitor completely prevents the degradation of endogenous GLP-1. This is in good agreement with our previous study (Deacon et al. 1998), in which DPP IV inhibition prevented degradation of exogenously infused 
GLP-1. However, it is interesting to note that GIP appears not to be protected to quite the same extent. Thus, with DPP IV inhibition, intact GIP increases to account for $90 \%$ of total GIP. It may be that GIP, in contrast to GLP-1, is a substrate for other N-terminally directed enzymes which are not inhibited by NVP-DPP728, a suggestion supported by a recent study indicating that DPP IV inhibition fails to completely protect exogenous GIP from degradation (Deacon et al. 2001). Moreover, unlike GLP-1, which is stored in the L-cell in the intact form (Hansen et al. 1999), there is some evidence that GIP is stored in both the intact form and as the N-terminally truncated metabolite, GIP (3-42) (Jörnvall et al. 1981). It may be that this peptide within the secretory granules is not accessible to the inhibitor or, alternatively, that the peptide which was released in response to the meal was already processed and stored within the granule prior to administration of the inhibitor. In this context, it would be interesting to inhibit the enzyme over a longer period so that de novo synthesis of GIP occurs, and see whether this leads to a more complete protection of the endogenous intact peptide.

In the present study, the pancreatic responses (insulin and glucagon) were not different between the two treatments (vehicle versus inhibitor), and there was only a marginal trend for the glucose excursion to be lower after the inhibitor. It might have been expected that increased amounts of biologically active incretins would lead to a potentiation in the insulin response. However, although the absolute concentrations of the active forms of both incretin hormones were elevated by the inhibitor, it should be noted that due to differences in the basal levels of GLP-1 on the inhibitor versus vehicle days, the relative increase in the amount of active GLP-1 was only marginal $(P=0 \cdot 08)$. This may provide part of the explanation for the lack of a potentiation of insulin secretion following the inhibitor, and further studies with larger numbers of animals should be able to clarify this. However, one can also argue that, in the normal animal, insulin secretion is already optimised to dispose of the glucose load, and since the incretin effect is glucose dependent (Weir et al. 1989), no additional effect of their presence would be noted. This would be in agreement with the available data in the limited number of studies so far undertaken to examine this issue. Thus, while a significant improvement in glucose tolerance in insulin-resistant obese Zucker rats given oral glucose is seen after both acute (Pederson et al. 1998, Balkan et al. 1999) and chronic (Brand et al. 1999) DPP IV inhibition, there was little or no effect on the glucose excursion in rats with normal glucose tolerance (Pederson et al. 1998, Balkan et al. 1999). Furthermore, it should also be remembered that plasma insulin levels reflect the combined result of several opposing events, i.e. the elevated levels of active incretins stimulate insulin secretion while, at the same time, the (marginally) lower blood glucose levels will tend to restrict insulin secretion.
In addition, it has been reported that the dog, in particular, can respond to a mixed meal challenge with little or no change in plasma glucose concentration (as found also in the present study), due to its ability to regulate precisely the rate of glucose appearance and disappearance (Strack et al. 1994).

In conclusion, the data presented show that inhibition of DPP IV largely prevents in vivo degradation of the endogenous incretin hormones, supporting the notion that the effects of DPP IV inhibitors are not due to protection of GLP-1 alone. Furthermore, DPP IV inhibition resulted in a net reduction in incretin hormone secretion without changes in insulin or glucose concentrations, raising the possibility that a feedback inhibitory mechanism acts to limit further secretion in the face of elevated levels of the biologically active forms.

\section{Acknowledgements}

This study was supported by grants from the Danish Medical Research Council, the Danish Biotechnology Programme and Grosserer Ernst Fischers Mindelegat. The technical assistance of Bodil Kristensen, Anne Mette Kragsig and Manisha Mone is gratefully acknowledged.

\section{References}

Ahrén B, Holst JJ, Martensson H \& Balkan B 2000 Improved glucose tolerance and insulin secretion by inhibition of dipeptidyl peptidase IV in mice. European Journal of Pharmacology 404 239-245.

Balkan B, Kwasnik L, Miserendino R, Holst JJ \& Li X 1999 Inhibition of dipeptidyl peptidase IV with NVP-DPP728 increases plasma GLP-1 (7-36 amide) concentrations and improves oral glucose tolerance in obese Zucker rats. Diabetologia 42 1324-1331.

Brand CL, Larsen PJ, Nielsen PF, Peschke B \& Carr RD 1999 Chronic administration of valine pyrrolidide, a selective inhibitor of dipeptidyl peptidase IV, improves glucose tolerance without affecting food intake in Zucker obese rats. Diabetes 48 (Suppl 1) 1186 (Abstract).

Brown JC, Mutt V \& Pederson RA 1970 Further purification of a polypeptide demonstrating enterogastrone activity. Journal of Physiology 209 57-64.

Brown JC, Buchan AM, McIntosh CH \& Pederson RA 1989 Gastric inhibitory polypeptide. In Handbook of Physiology, pp 403-430. Eds SG Schulz, GM Maklouf \& BB Rauner. Bethesda, MD: American Physiological Society.

Brubaker PL, Efendic S \& Greenberg GR 1997 Truncated and full-length glucagon-like peptide-1 (GLP-1) differentially stimulate intestinal somatostatin release. Endocrine 6 91-95.

Creutzfeldt W \& Ebert R 1985 New developments in the incretin concept. Diabetologia 28 565-573.

Deacon CF, Johnsen AH \& Holst JJ 1995a Degradation of glucagon-like peptide-1 by human plasma in vitro yields an N-terminally truncated peptide which is a major endogenous metabolite in vivo. Journal of Clinical Endocrinology and Metabolism 80 952-957.

Deacon CF, Nauck MA, Toft-Nielsen M, Pridal L, Willms B \& Holst JJ $1995 b$ Both subcutaneously and intravenously administered glucagon-like peptide-1 are rapidly degraded from the $\mathrm{NH}_{2}$-terminus in type II diabetic patients and in healthy subjects. Diabetes 44 1126-1131. 
Deacon CF, Hughes TE \& Holst JJ 1998 Dipeptidyl peptidase IV inhibition potentiates the insulinotropic effect of glucagon-like peptide-1 in the anesthetized pig. Diabetes 47 764-769.

Deacon CF, Nauck MA, Meier J, Hücking K \& Holst JJ 2000 Degradation of endogenous and exogenous gastric inhibitory polypeptide (GIP) in healthy and in Type 2 diabetic subjects as revealed using a new assay for the intact peptide. Journal of Clinical Endocrinology and Metabolism 85 3575-3581.

Deacon CF, Danielsen P, Klarskov L, Olesen M \& Holst JJ 2001 Dipeptidyl peptidase IV inhibition reduces the degradation and clearance of GIP and potentiates its insulinotropic and antihyperglycemic effects in anesthetized pigs. Diabetes $\mathbf{5 0}$ 1588-1597.

Dyrberg T \& Kofod H 1990 Synthetic peptides as antigen. In Animal Virus Pathogenesis - A Practical Approach, pp 163-171. Ed MBA Oldstone. Oxford: IRL Press.

Hansen L, Deacon CF, Ørskov C \& Holst JJ 1999 Glucagon-like peptide-1-(7-36)amide is transformed to glucagon-like peptide-1-(9-36)amide by dipeptidyl peptidase IV in the capillaries supplying the L cells of the porcine intestine. Endocrinology 140 $5356-5363$.

Hansen L, Hartmann B, Bisgaard T, Mineo H, Jorgensen PN \& Holst JJ 2000 Somatostatin restrains the secretion of glucagon-like peptide-1 and -2 from isolated perfused porcine ileum. American Journal of Physiology 278 E1010-E1018.

Holst JJ 1997 Enteroglucagon. Annual Review of Physiology 59 257-271.

Holst JJ \& Deacon CF 1998 Inhibition of the activity of dipeptidyl-peptidase IV as a treatment for type 2 diabetes. Diabetes 47 1663-1670.

Hughes TE, Mone MD, Russell ME, Weldon SC \& Villhauer EB 1999 NVP-DPP728 (1-[[[2-[(5-cyanopyridin-2-yl)amino]ethyl]amino]acetyl]-2-cyano-(S)-pyrrolidine), a slow-binding inhibitor of dipeptidyl peptidase IV. Biochemistry 38 11597-11603.

Jörnvall $\mathrm{H}$, Carlquist M, Kwauk S, Otte SC, McIntosh CH, Brown JC \& Mutt V 1981 Amino acid sequence and heterogeneity of gastric inhibitory polypeptide (GIP). FEBS Letters 123 205-210.

Kieffer TJ, McIntosh CHS \& Pederson RA 1995 Degradation of glucose-dependent insulinotropic polypeptide (GIP) and truncated glucagon-like peptide 1 (tGLP-1) in vitro and in vivo by dipeptidyl peptidase IV. Endocrinology 136 3585-3596.

Knudsen LB \& Pridal L 1996 Glucagon-like peptide-1 (9-36)amide is a major metabolite of glucagon-like peptide-1 (7-36)amide after in vivo administration to dogs, and it acts as an antagonist on the pancreatic receptor. European Journal of Pharmacology 318 429-435.

Krarup T \& Holst JJ 1984 The heterogeneity of gastric inhibitory polypeptide in porcine and human gastrointestinal mucosa evaluated with five different antisera. Regulatory Peptides 9 35-46.

Krarup T, Madsbad S, Moody AJ, Regeur L, Faber OK, Holst JJ \& Sestoft L 1983 Diminished immunoreactive gastric inhibitory polypeptide response to a meal in newly diagnosed type I (insulin-dependent) diabetics. Journal of Clinical Endocrinology and Metabolism 56 1306-1312.

Mentlein R, Gallwitz B \& Schmidt WE 1993 Dipeptidyl peptidase IV hydrolyses gastric inhibitory polypeptide, glucagon-like peptide-1 (7-36)amide, peptide histidine methionine and is responsible for their degradation in human serum. European Journal of Biochemistry 214 829-835.

Miyawaki K, Yamada Y, Yano H, Niwa H, Ban N, Ihara Y, Kubota A, Fujimoto S, Kajikawa M, Kuroe A, Tsuda K, Hashimoto H, Yamashita T, Jomori T, Tashiro F, Miyazaki J \& Seino Y 1999 Glucose intolerance caused by a defect in the entero-insular axis: a study in gastric inhibitory polypeptide receptor knockout mice. PNAS 96 14843-14847.

Mojsov S, Weir GC \& Habener JF 1987 Insulinotropin: glucagon-like peptide I (7-37) co-encoded in the glucagon gene is a potent stimulator of insulin release in the perfused rat pancreas. Journal of Clinical Investigation 79 616-619.
Nauck MA, Bartels E, Ørskov C, Ebert R \& Creutzfeldt W 1993 Additive insulinotropic effects of exogenous synthetic human gastric inhibitory polypeptide and glucagon-like peptide-1-(7-36) amide infused at near-physiological insulinotropic hormone and glucose concentrations. Journal of Clinical Endocrinology and Metabolism 76 912-917.

Ørskov C, Holst JJ, Seier Poulsen S \& Kirkegaard P 1987 Pancreatic and intestinal processing of proglucagon in man. Diabetologia $\mathbf{3 0}$ 874-881.

Ørskov C, Bersani M, Johnsen AH, Højrup P \& Holst JJ 1989 Complete sequences of glucagon-like peptide-1 from human and pig small intestine. Journal of Biological Chemistry 264 12826-12829.

Ørskov C, Jeppesen J, Madsbad S \& Holst JJ 1991 Proglucagon products in the plasma of non-insulin dependent diabetics and nondiabetic controls in the fasting state and following oral glucose and intravenous arginine. Journal of Clinical Investigation 87 415-423.

Ørskov C, Wettergren A \& Holst JJ 1993 Effects and metabolic rates of glucagonlike peptide-1 7-36 amide and glucagonlike peptide-1 7-37 in healthy subjects are indistinguishable. Diabetes 42 658-661.

Ørskov C, Rabenhøj L, Wettergren A, Kofod H \& Holst JJ 1994

Tissue and plasma concentrations of amidated and glycine-extended glucagon-like peptide-1 in humans. Diabetes 43 535-539.

Pauly RP, Rosche F, Wermann M, McIntosh CH, Pederson RA \& Demuth HU 1996 Investigation of glucose-dependent insulinotropic polypeptide-(1-42) and glucagon-like peptide-1-(7-36) degradation in vitro by dipeptidyl peptidase IV using matrix-assisted laser desorption/ionization-time of flight mass spectrometry. A novel kinetic approach. Journal of Biological Chemistry 271 23222-23229.

Pederson RA, White HA, Schlenzig D, Pauly RP, McIntosh CH \& Demuth HU 1998 Improved glucose tolerance in Zucker fatty rats by oral administration of the dipeptidyl peptidase IV inhibitor isoleucine thiazolidide. Diabetes 47 1253-1258.

Rothenberg P, Kalbag J, Smith H, Gingerich R, Nedelman J, Villhauer E, McLeod J \& Hughes T 2000 Treatment with a DPP-IV inhibitor, NVP-DPP728, increases prandial intact GLP-1 levels and reduces glucose exposure in humans. Diabetes 49 (Suppl 1) A39 (Abstract).

Scrocchi LA, Marshall BA, Cook SM, Brubaker PL \& Drucker DJ 1998 Identification of glucagon-like peptide 1 (GLP-1) actions essential for glucose homeostasis in mice with disruption of GLP-1 receptor signaling. Diabetes 47 632-639.

Stockmann F, Ebert R \& Creutzfeldt W 1984 Preceding hyperinsulinemia prevents demonstration of insulin effect on fat-induced gastric inhibitory polypeptide (GIP). Diabetes 33 580-585.

Strack TR, Poussier P, Marliss EB \& Albisser AM 1994 Glucose turnover after a mixed meal in dogs: glucoregulation without change in arterial glycemia. American Journal of Physiology 266 R889-R895.

Toft-Nielsen MB, Madsbad S \& Holst JJ 1999 Continuous subcutaneous infusion of glucagon-like peptide 1 lowers plasma glucose and reduces appetite in type 2 diabetic patients. Diabetes Care 22 1137-1143.

Weir GC, Mojsov S, Hendrick GK \& Habener JF 1989 Glucagon-like peptide 1 (7-37) actions on endocrine pancreas. Diabetes $\mathbf{3 8}$ $338-342$.

Wettergren A, Schjoldager B, Mortensen PE, Myhre J, Christiansen J \& Holst JJ 1993 Truncated GLP-1 (proglucagon 78-107 amide) inhibits gastric and pancreatic functions in man. Digestive Diseases and Science 38 665-673.

Wettergren A, Pridal L, Wojdemann M \& Holst JJ 1998 Amidated and non-amidated glucagon-like peptide-1 (GLP-1): non-pancreatic effects (cephalic phase acid secretion) and stability in plasma in humans. Regulatory Peptides 77 83-87.

Received 3 July 2001

Accepted 4 October 2001 